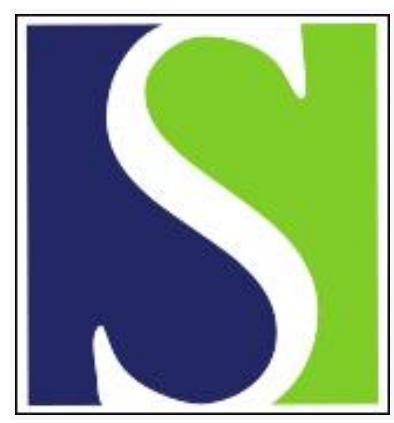

Scand J Work Environ Health 2004;30(5):390-398

https://doi.org/10.5271/sjweh.827

Issue date: Oct 2004

Computer users' risk factors for developing shoulder, elbow and back symptoms

by Juul-Kristensen B, Søgaard K, Strøyer J, Jensen C

Affiliation: National Institute of Occupational Health, Lersø Parkallé 105, DK-2100 Copenhagen Ø, Denmark. bjk@ami.dk

Refers to the following texts of the Journal: 1998;24(5):418-424

2003;29(3):197-205 2002;28(1):18-24 1995;21(6):427-434

1999;25(5):387-403

The following articles refer to this text: 2008;34(1):55-65;

2008;34(5):345-355; 2009;35(2):134-144; 2011;37(3):196-203

Key terms: back symptom; behavior; computer user; computer work; elbow symptom; follow-up study; glare; information technology; musculoskeletal symptom; pause; prospective study; reflection; risk factor; screen height; shoulder symptom

This article in PubMed: www.ncbi.nlm.nih.gov/pubmed/15529802

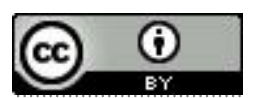




\title{
Computer users' risk factors for developing shoulder, elbow and back symptoms
}

\author{
by Birgit Juul-Kristensen, PhD, ${ }^{1}$ Karen Søgaard, PhD, ${ }^{1}$ Jesper Strøyer, MSc, ${ }^{1}$ Chris Jensen, PhD ${ }^{1}$
}

Juul-Kristensen B, Søgaard K, Strøyer J, Jensen C. Computer users' risk factors for developing shoulder, elbow and back symptoms. Scand J Work Environ Health 2004;30;5):390-398.

Objectives This prospective study concentrated on determining factors of computer work that predict musculoskeletal symptoms in the shoulder, elbow, and low-back regions.

Methods A questionnaire on ergonomics, work pauses, work techniques, and psychosocial and work factors was delivered to 5033 office workers at baseline in early 1999 (response rate 69\%) and to 3361 respondents at the time of the follow-up in late 2000 (response rate 77\%). An increased frequency or intensity of symptoms was the outcome variable, including only nonsymptomatic respondents from the baseline questionnaire (symptom frequency below 8 days within the last 12 months or intensity score below 4 within the last 3 months).

Results In the follow-up, $10 \%, 18 \%$, and $23 \%$ had symptoms more often in the elbow, shoulder, and low back, respectively, and $14 \%, 20 \%$, and $22 \%$ had more intense symptoms. Women were more likely to be afflicted than men in all regions. In the full-fit multivariate logistic regression analysis, little influence on the timing of a rest pause and being disturbed by glare or reflection were significant predictors of shoulder symptoms, screen below eye height was a significant predictor for elbow symptoms, and previous symptoms was a significant predictor for symptoms in all regions. Computer worktime and psychosocial dimensions were not significant predictors. Conclusions Influence on work pauses, reduction of glare or reflection, and screen height are important factors in the design of future computer workstations. Since previous symptoms was a significant predictor of recurrent symptoms in all three regions under study, it can be concluded that musculoskeletal symptoms are persistent.

Key terms computer work, Behavior in Information Technology follow-up study, glare, reflection, musculoskeletal symptoms, pause, prospective study, screen height.

In general, both physical and psychosocial factors of computer work, including daily duration of computer work, repetitive movements, static and nonneutral wrist, arm and neck work postures, lack of variation and psychosocial factors, have been found to be risk factors for musculoskeletal symptoms in different regions of the body $(1,2)$. In an extensive review of epidemiologic findings among computer users, evidence was found for determinants of postural strain, such as poor workstation ergonomics, to be involved in musculoskeletal problems among computer users, but, as mentioned earlier, most of the evidence is based on the results of crosssectional studies (3). Most of the studies have concerned symptoms in the neck and shoulder, while few studies have focused on the elbow or low back.
Although it is well known that, in many precisiondemanding computer tasks, shoulder muscles must work as stabilizers, and thereby they primarily perform static work $(4,5)$, a limited number of prospective studies on risk factors for symptoms in the neck or shoulder have been carried out among computer users. A 2-year follow-up study of 2500 computer users, called the BIT (Behavior in Information Technology) study, with the same population as in our present study found that screen height above eye level was a significant predictor of neck symptoms among women (6). In addition to physical factors, previous symptoms and little influence at work were predictors of symptoms in the neck and hand-wrist region (6). In another prospective study of 632 newly hired computer users, keying with the elbow

Correspondence to: Dr Birgit Juul-Kristensen, National Institute of Occupational Health, Lersø Parkallé 105, DK-2100 Copenhagen Ø, Denmark. [E-mail: bjk@ami.dk] 
below the height of the " $\mathrm{J}$ " key and the presence of a telephone shoulder rest were associated with an increased risk of neck-shoulder symptoms or disorders (7). A recent prospective study of 180 workers who used video display units (VDU) found a poor physical work environment and a poor placement of the keyboard to be predictors of neck pain (8).

Risk factors for symptoms in the elbow have been found to be forceful movements and the combination of force, repetitiveness, and nonneutral postures $(9,10)$, but contradictory results have been published with respect to computer work and the development of elbow pain. A prospective study of 5658 computer users (NUDATA study) showed that intensive use of a mouse ( $>20$ hours a week) was a predictor of pain in the forearm, but with very few clinical signs in the forearm (11). A recent case-referent study (267 cases and 388 referents) found nonneutral postures, repetition, and, for women, low social support to be related to epicondylitis, while the results for precision-demanding movements were less consistent, because of the lack of exposed persons (10). Furthermore, individual factors, such as age, work seniority, and previous elbow complaints, had a significant influence (12).

Nonneutral work postures have been found to be risk factors for low-back symptoms in addition to lifting, forceful movements, heavy physical work, and wholebody vibration (9), but little has been published with regard to sitting and, especially, computer work in relation to the development of low-back symptoms. In a review (13), sitting at work was not associated with lowback pain when compared with standing, lifting and bending in seven studies. One cross-sectional study from this review found that the "poorer" the sitting habits, the higher the 1-year prevalence of low-back pain, but "poor sitting habits" was not defined (14). Another cross-sectional study from the review found that specific tasks performed while sitting (rather than sitting itself) in ergonomically unfit chairs were associated with low-back pain (15). In a 5-year follow-up study people changed jobs from physically hard work to sedentary work to a higher extent when having developed low-back pain, and sitting was therefore suggested to have a protective or neutral effect on the low back (16).

Altogether, few prospective studies have shown that factors related to computer work are significant predictors of musculoskeletal symptoms in the shoulder, elbow, and low back. The aim of this study was to investigate self-reported factors related to computer work in a prospective study as possible predictors of future musculoskeletal symptoms in shoulder, elbow, and low back. The main hypothesis was that the duration of worktime with a computer, ergonomic and psychosocial factors, other than individual factors, were risk factors for the development of symptoms in the shoulder, elbow, and low back.

\section{Study population and methods}

\section{Study population}

A baseline questionnaire concerning physical and psychosocial work conditions and health status was given to 5033 office workers in Denmark in the beginning of 1999 , and $69 \%$ responded $(\mathrm{N}=3475)$. The target population was represented by a total of 11 Danish companies and institutions employing computer users, and the companies were selected to provide employees with different types of computer work (ie, data entry, word processing, graphic work, etc). The employees of the participating companies were computer users with different types of computer work, but the distribution of computer use or worktasks could not be assumed to be strictly representative of office work in general. All the employees of an entire company or in specific predefined departments were included, except cleaning and kitchen personnel. The questionnaires were returned in sealed envelopes at their workplace and later collected by a representative from the National Institute of Occupational Health. Results from the cross-sectional study concerning psychosocial, physical, and individual factors and symptoms related to the duration of computer and mouse use have been presented previously $(17,18)$. A follow-up questionnaire primarily consisting of questions on health status was mailed at the end of 2000 to 3471 of the earlier respondents, whose home address was known from the baseline questionnaire. Of these, 108 respondents had changed their home address and were not traceable through postal service registers at the time of the follow-up. Thus 3363 respondents were finally assumed to have received the follow-up questionnaire, and 2576 people responded, corresponding to a response rate of $77 \%$. The mean follow-up period was 21 (range 17-23) months. Risk factors for neck and hand-wrist symptoms (6) have been focused on in another paper on the follow-up study. The questionnaires distributed at baseline and at the time of the follow-up contained questions on musculoskeletal symptoms (trouble, ache or pain, here denoted as symptoms) according to a modified version of the Nordic questionnaire (19).

We used two outcome parameters separately. First, case definition was defined by an increase in the frequency of days with musculoskeletal symptoms during the last 12 months, from $<8$ days in the baseline questionnaire (nonsymptomatic) to $>7$ days in the follow-up questionnaire (symptomatic). Frequency has been used as the outcome parameter in many recent epidemiologic and intervention studies $(6,20,21)$, and it is, therefore, a variable that can be compared with the findings in other datasets. Second, case definition was defined by an increase in the mean intensity of musculoskeletal symptoms during the last 3 months, from $<4$, rated on a 
scale from 0 to 9 , to $\geq 4$. The validity and reproducibility of this question has been tested and found to be satisfactory with respect to the 3 -month period used in our study $(22,23)$. The case definitions for the shoulder and elbow stated that the participants had to change from nonsymptomatic on both the right and the left sides at baseline to symptomatic either on the right, the left, or both sides. The included workers also had to be nonsymptomatic in the nearby body regions at baseline, meaning, for the shoulder, also in the neck and elbow regions, for the elbow, also in the shoulder and hand, and, for the low back, also in the neck region.

\section{Exposure parameters from the questionnaire}

The exposure parameters from the baseline questionnaire consisted of physical, psychosocial, work-related, and individual questions. The physical parameters included the six ergonomic parameters of (i) whether the chair had been individually adjusted (yes, no), (ii) whether the desk had been individually adjusted (yes, no), (iii) whether there was enough space to rest the arms on the desk in front of the keyboard (yes, no), (iv) whether the upper line of the mostly used screen was below eye height (yes, no), (v) how much of the worktime was spent standing up at the desk (six categories dichotomized to never versus seldom-to- $100 \%$ of the time), and (vi) how often there were disturbances of glare or reflection on the screen (four categories dichotomized as everyday-to-sometimes a week versus nowand-then to never). Additional physical parameters were included, consisting of the influence on when to take a rest pause (five categories dichotomized to always-tooften versus sometimes-to-never) and how often it was necessary to work very fast (five categories dichotomized to never-to-sometimes versus often-to-always).

Psychosocial dimensions were assessed by the construction of indices based on the answer to three to seven different questions, each with five response categories (never, seldom, sometimes, often, always). The indices ranged from 0 to 100 for each factor (24). The psychosocial dimensions included the following five indices: cognitive demands ( 7 questions on decision making, memory demands, creativity and responsibilities, Cronbach's alpha $=0.83$ ), sensory demands, ( 3 questions on visual demands, precision and attentiveness, Cronbach's alpha $=0.70$ ), influence at work ( 7 questions on influence on what, how and when work is done, influence on quality of work and on who the work is done with, Cronbach's alpha $=0.76$ ), developmental possibilities (5 questions on skill demands, development of skills, demands for taking initiative and lack of monotony, Cronbach's alpha $=0.81$ ), and social support (4 questions on support from colleagues and superiors, Cronbach's alpha $=0.71$ ).
Furthermore, questions related to worktime with a computer (four categories) and three individual factors (gender, age, and previous symptoms) were included in the analyses.

\section{Statistics}

The data were analyzed for associations between the exposure parameters reported at baseline and an increased frequency or intensity of symptoms in the shoulder, elbow, or low back at the time of the follow-up. Multivariate logistic regression analyses were performed on three submodels, and a full-fit model, including a work-factor submodel (work time with the computer), an ergonomic submodel (chair, desk, armrest space, screen height, standing work, glare or reflection, influence of workpauses, necessity to work fast), a psychosocial submodel (cognitive and sensory demands, influence at work in general, developmental possibilities and social support), and a full-fit model including all the variables from the work-factor, ergonomic, and psychosocial submodels, including the variable of previous symptoms. Adjustment for gender and age was performed in all the logistic regression analyses. The final logistic regression models were recalculated using only the respondents that did not change jobs between the baseline examination and the follow-up. The procedures proc FREQ, MEAN and GENMOD in SAS (version 8.2, SAS Institute Inc, Cary, NC, USA) were used.

\section{Results}

Of the respondents, $20 \%$ at baseline and $25 \%$ at followup had symptoms for $>7$ days in four or more regions, and the mean number of symptomatic regions was 1.8 in the baseline examination and 2.1 at the time of the follow-up. With regard to the intensity of pain, the mean intensity at baseline was 1.5 , and at follow-up it was 1.8 . Of those who were defined as nonsymptomatic at baseline, $18 \%, 10 \%$, and $23 \%$ showed an increase in the frequency of symptom days (table 1) for the shoulder, elbow, low-back region, respectively, at the time of the follow-up. In the follow-up, 20\%, 14\%, and $22 \%$ of those who were defined as nonsymptomatic at baseline had an increased intensity of musculoskeletal symptoms in the shoulder, elbow, and low-back regions, respectively (table 1). For all the regions, a higher percentage of women than men had undergone a change (table 1). For both the frequency and intensity outcomes, the region with the highest incidence was the low back, and the lowest incidence was found for the elbow region. The distribution of all the studied variables is presented in tables 2 and 3. 
Table 1. Number of men and women who experienced musculoskeletal symptoms between the baseline and the follow-up examinations according to the frequency and intensity of the symptoms.

\begin{tabular}{|c|c|c|c|c|c|c|c|c|}
\hline & \multicolumn{3}{|c|}{ Men } & \multicolumn{3}{|c|}{ Women } & \multicolumn{2}{|c|}{ Total } \\
\hline & $\mathrm{N}$ & $\%$ & $\mathrm{~N}_{\text {total }}$ & $\mathrm{N}$ & $\%$ & $\mathrm{~N}_{\text {total }}$ & $\mathrm{N}$ & $\% \quad \mathrm{~N}_{\text {total }}$ \\
\hline \multicolumn{9}{|c|}{$\geq 8$ days with musculoskeletal symptoms during last 12 months a } \\
\hline $\begin{array}{l}\text { Shoulder } \\
\text { Elbow } \\
\text { Low back }\end{array}$ & $\begin{array}{l}57 \\
38 \\
95\end{array}$ & $\begin{array}{r}11 \\
7 \\
20\end{array}$ & $\begin{array}{l}496 \\
547 \\
484\end{array}$ & $\begin{array}{r}141 \\
94 \\
154\end{array}$ & $\begin{array}{l}22 \\
12 \\
27\end{array}$ & $\begin{array}{l}627 \\
787 \\
580\end{array}$ & $\begin{array}{l}198 \\
132 \\
249\end{array}$ & $\begin{array}{ll}18 & 1123 \\
10 & 1334 \\
23 & 1064\end{array}$ \\
\hline \multicolumn{9}{|c|}{$\geq 4$ in intensity score of musculoskeletal symptoms during last 3 months } \\
\hline $\begin{array}{l}\text { Shoulder } \\
\text { Elbow } \\
\text { Low back }\end{array}$ & $\begin{array}{r}77 \\
58 \\
111\end{array}$ & $\begin{array}{l}13 \\
10 \\
20\end{array}$ & $\begin{array}{l}574 \\
604 \\
568\end{array}$ & $\begin{array}{l}191 \\
150 \\
193\end{array}$ & $\begin{array}{l}24 \\
17 \\
24\end{array}$ & $\begin{array}{l}791 \\
865 \\
803\end{array}$ & $\begin{array}{l}268 \\
208 \\
304\end{array}$ & $\begin{array}{ll}20 & 1365 \\
14 & 1469 \\
22 & 1371\end{array}$ \\
\hline
\end{tabular}

Table 2. Distribution of the individual and physical exposure variables among the participants.

\begin{tabular}{|c|c|c|}
\hline Variable & $\mathrm{N}$ & $\%$ \\
\hline \multicolumn{3}{|l|}{ Gender } \\
\hline Men & 766 & 39 \\
\hline Women & 1221 & 61 \\
\hline \multicolumn{3}{|l|}{ Age } \\
\hline$>50$ years & 705 & 35 \\
\hline 40-49 years & 600 & 30 \\
\hline 30-39 years & 489 & 25 \\
\hline $18-29$ years & 193 & 10 \\
\hline \multicolumn{3}{|l|}{ Worktime with computer } \\
\hline$<25 \%$ of the time never & 302 & 15 \\
\hline $50 \%$ of the time & 369 & 19 \\
\hline $75 \%$ of the time & 470 & 24 \\
\hline Almost all the time & 822 & 42 \\
\hline \multicolumn{3}{|l|}{ Chair adjusted } \\
\hline No & 181 & 11 \\
\hline Yes & 1528 & 89 \\
\hline \multicolumn{3}{|l|}{ Desk adjusted } \\
\hline No & 319 & 19 \\
\hline Yes & 1381 & 81 \\
\hline \multicolumn{3}{|l|}{ Armrest space } \\
\hline No & 529 & 27 \\
\hline Yes & 1405 & 73 \\
\hline \multicolumn{3}{|l|}{ Screen below eye height } \\
\hline No & 587 & 30 \\
\hline Yes & 1351 & 70 \\
\hline \multicolumn{3}{|l|}{ Standing } \\
\hline Never & 839 & 43 \\
\hline Seldom-to-always & 1129 & 57 \\
\hline \multicolumn{3}{|l|}{ Glares or reflection } \\
\hline Everyday-to-some times & 356 & 18 \\
\hline Now and then-to-none & 1569 & 82 \\
\hline \multicolumn{3}{|l|}{ Work pause } \\
\hline Small influence & 492 & 25 \\
\hline Large influence & 1473 & 75 \\
\hline \multicolumn{3}{|l|}{ Necessary to work fast } \\
\hline Always-to-some times & 1178 & 60 \\
\hline Seldom-to-never & 796 & 40 \\
\hline
\end{tabular}

Table 3. Distribution of the psychosocial and exposure variables among the participants.

\begin{tabular}{lccc}
\hline Variable & \multirow{2}{*}{ N } & \multicolumn{2}{c}{ Index value } \\
\cline { 3 - 4 } & & Mean & SD \\
\hline Cognitive demands & 1969 & 59 & 18 \\
Sensory demands & 1972 & 74 & 20 \\
Influence at work & 1965 & 60 & 18 \\
Developmental possibilities & 1971 & 67 & 19 \\
Social support & 1965 & 62 & 19 \\
\hline
\end{tabular}

There was a tendency for worktime with a computer to be a predictor of symptoms in the lower back (table 4). In the ergonomic submodel (table 4), the influence of workpauses and being disturbed by glare or reflection were significant predictors of symptom development in the shoulder, and work with a screen below eye height predicted symptom development in the elbow. The influence of workpauses showed a tendency towards significance for symptoms in the lower back. In the psychosocial submodel (table 4) influence at work and developmental possibilities were significant predictors of symptoms in the shoulder, cognitive demands predicted symptoms in the elbow, and influence at work was a significant predictor for symptoms in the lower back.

In the final model, the full-fit multivariate logistic regression model (table 4), none of the psychosocial dimensions were significant predictors. Having had previous symptoms was significant for symptom development in all regions, both with respect to frequency and intensity, and previous symptoms were also the only significant predictor of symptoms in the back. Furthermore, the influence on workpauses and being disturbed by glare or reflection were significant predictors of symptoms in the shoulder, whereas work with a screen below eye height and a small necessity to work fast were significant predictors for symptoms in the elbow. In general, the highest odds ratios were having had previous symptoms 1-7 days during the last 12 months [odds ratio (OR) 1.40-4.45], little influence on the timing of workpauses (OR 1.87), and work with a screen below eye height (OR 1.85). None of the odds ratios changed markedly when adjusted for those who had the same job at follow-up.

\section{Discussion}

Having had previous symptoms 1-7 days during the last 12 months was a significant predictor of symptoms in all the body regions studied, little influence on the timing of workpauses, and being disturbed by glare or reflection were significant predictors of symptoms in the 
Table 4. Logistic regression models for respondents with a higher frequency of days and a higher intensity of musculoskeletal symptoms at follow up in relation to work-related factors (adjusted for gender and age). (OR = odds ratio, $95 \% \mathrm{Cl}=95 \%$ confidence interval)

\begin{tabular}{|c|c|c|c|c|c|c|c|c|c|}
\hline \multirow[t]{2}{*}{ Exposure factors } & \multicolumn{3}{|c|}{ Shoulder } & \multicolumn{3}{|c|}{ Elbow } & \multicolumn{3}{|c|}{ Low back } \\
\hline & $\mathrm{OR}$ & $95 \% \mathrm{Cl}$ & P-value ${ }^{a}$ & $\mathrm{OR}$ & $95 \% \mathrm{Cl}$ & P-value a & $\mathrm{OR}$ & $95 \% \mathrm{Cl}$ & P-value a \\
\hline \multicolumn{10}{|l|}{ Work factor model } \\
\hline \multicolumn{10}{|l|}{ Frequency } \\
\hline Worked $50 \%$ of the time ${ }^{b}$ & 1.31 & $0.76-2.28$ & 0.67 & 1.01 & $0.53-1.94$ & 0.97 & 0.94 & $0.57-1.55$ & 0.51 \\
\hline Worked $75 \%$ of the time & 1.22 & $0.72-2.08$ &.. & 0.97 & $0.52-1.81$ & .. & 1.03 & $0.64-1.65$ & .. \\
\hline Worked almost all the time ${ }^{b}$ & 1.06 & $0.63-1.77$ & .. & 1.08 & $0.60-1.93$ & .. & 1.25 & $0.80-1.95$ & .. \\
\hline \multicolumn{10}{|l|}{ Intensity } \\
\hline Worked $50 \%$ of the time ${ }^{b}$ & 1.23 & $0.76-1.99$ & 0.42 & 1.47 & $0.86-2.49$ & 0.13 & 0.86 & $0.54-1.36$ & 0.092 \\
\hline Worked $75 \%$ of the time ${ }^{b}$ & 1.01 & $0.63-1.62$ & .. & 1.02 & $0.59-1.76$ & .. & 1.02 & $0.66-1.59$ & .. \\
\hline Worked almost all the time ${ }^{b}$ & 1.31 & $0.84-2.04$ & .. & 1.50 & $0.92-2.47$ & .. & 1.35 & $0.89-2.03$ & .. \\
\hline \multicolumn{10}{|l|}{ Ergonomic model } \\
\hline \multicolumn{10}{|l|}{ Frequency } \\
\hline No adjusted chair & 1.46 & $0.75-2.83$ & 0.27 & 0.82 & $0.38-1.77$ & 0.61 & 1.46 & $0.80-2.67$ & 0.22 \\
\hline No adjusted desk & 0.69 & $0.37-1.29$ & 0.24 & 1.10 & $0.57-2.14$ & 0.77 & 0.84 & $0.48-1.44$ & 0.52 \\
\hline No armrest space & 0.98 & $0.62-1.55$ & 0.93 & 1.04 & $0.62-1.74$ & 0.89 & 1.04 & $0.68-1.58$ & 0.86 \\
\hline Screen below eye height & 1.02 & $0.68-1.51$ & 0.94 & 1.79 & $1.10-2.93$ & 0.015 & 1.20 & $0.83-1.74$ & 0.32 \\
\hline Never standing & 1.09 & $0.72-1.65$ & 0.67 & 0.81 & $0.51-1.28$ & 0.38 & 1.04 & $0.72-1.50$ & 0.83 \\
\hline Glares or reflection & 1.21 & $0.76-1.92$ & 0.43 & 1.24 & $0.74-2.07$ & 0.43 & 0.94 & $0.59-1.50$ & 0.79 \\
\hline Pauses, small influence & 1.50 & $0.94-2.39$ & 0.090 & 1.17 & $0.70-1.96$ & 0.55 & 1.36 & $0.88-2.11$ & 0.17 \\
\hline Necessary to work fast & 1.08 & $0.72-1.61$ & 0.72 & 1.30 & $0.82-2.04$ & 0.26 & 1.04 & $0.72-1.48$ & 0.84 \\
\hline \multicolumn{10}{|l|}{ Intensity } \\
\hline No adjusted chair & 1.29 & $0.74-2.26$ & 0.37 & 1.20 & $0.62-2.32$ & 0.60 & 1.11 & $0.65-1.91$ & 0.70 \\
\hline No adjusted desk & 1.09 & $0.66-1.80$ & 0.73 & 0.90 & $0.50-1.63$ & 0.73 & 1.15 & $0.72-1.83$ & 0.56 \\
\hline No armrest space & 1.06 & $0.71-1.57$ & 0.78 & 0.94 & $0.60-1.46$ & 0.77 & 0.92 & $0.63-1.35$ & 0.66 \\
\hline Screen below eye height & 1.13 & $0.79-1.60$ & 0.51 & 1.22 & $0.82-1.81$ & 0.32 & 0.98 & $0.70-1.36$ & 0.89 \\
\hline Never standing & 1.07 & $0.76-1.52$ & 0.70 & 0.84 & $0.57-1.23$ & 0.37 & 1.07 & $0.77-1.49$ & 0.70 \\
\hline Glares or reflection & 1.51 & $1.04-2.20$ & 0.034 & 1.30 & $0.84-2.01$ & 0.25 & 1.19 & $0.81-1.74$ & 0.38 \\
\hline Pauses, small influence & 1.54 & $1.03-2.31$ & 0.038 & 1.31 & $0.83-2.05$ & 0.24 & 1.41 & $0.95-2.10$ & 0.087 \\
\hline Necessary to work fast & 0.99 & $0.70-1.40$ & 0.96 & 0.68 & $0.47-1.00$ & 0.048 & 1.20 & $0.86-1.67$ & 0.27 \\
\hline \multicolumn{10}{|c|}{ Psychosocial model (dimensions covering indices $0-100$ ) } \\
\hline \multicolumn{10}{|l|}{ Frequency } \\
\hline Cognitive demands & 1.00 & $0.99-1.01$ & 0.87 & 1.02 & $1.00-1.03$ & 0.040 & 1.01 & $0.99-1.02$ & 0.28 \\
\hline Sensory demands & 1.01 & $1.00-1.02$ & 0.094 & 1.00 & $0.99-1.01$ & 0.82 & 1.00 & $0.99-1.01$ & 0.65 \\
\hline Influence at work & 0.99 & $0.98-0.99$ & 0.036 & 0.99 & $0.98-1.00$ & 0.24 & 0.99 & $0.98-1.00$ & 0.053 \\
\hline Developmental possibilities & 1.00 & $0.99-1.02$ & 0.66 & 0.99 & $0.98-1.01$ & 0.35 & 0.99 & $0.98-1.01$ & 0.33 \\
\hline Social support & 1.00 & $0.99-1.01$ & 0.93 & 1.00 & $0.99-1.01$ & 0.56 & 1.00 & $1.00-1.01$ & 0.40 \\
\hline \multicolumn{10}{|l|}{ Intensity } \\
\hline Cognitive demands & 1.01 & $1.00-1.02$ & 0.12 & 1.01 & $1.00-1.02$ & 0.18 & 1.00 & $0.99-1.01$ & 0.45 \\
\hline Sensory demands & 1.00 & $0.99-1.01$ & 0.97 & 1.00 & $0.99-1.01$ & 0.53 & 1.00 & $1.00-1.01$ & 0.23 \\
\hline Influence at work & 0.99 & $0.98-1.00$ & 0.14 & 0.99 & $0.98-1.00$ & 0.18 & 0.99 & $0.98-1.00$ & 0.16 \\
\hline Developmental possibilities & 0.99 & $0.98-1.00$ & 0.039 & 0.99 & $0.98-1.00$ & 0.17 & 1.00 & $0.99-1.01$ & 0.45 \\
\hline Social support & 1.00 & $0.99-1.01$ & 0.93 & 1.00 & $0.99-1.01$ & 0.79 & 1.00 & $0.99-1.01$ & 0.65 \\
\hline Full-fit model & & & & & & & & & \\
\hline Frequency & & & & & & & & & \\
\hline Worked $50 \%$ of the time ${ }^{b}$ & 1.23 & $0.63-2.40$ & 0.29 & 1.11 & $0.51-2.40$ & 0.97 & 0.83 & $0.46-1.51$ & 0.73 \\
\hline Worked $75 \%$ of the time ${ }^{b}$ & 1.00 & $0.51-1.94$ &.. & 0.95 & $0.43-2.10$ & .. & 0.90 & $0.50-0.61$ &.. \\
\hline Worked almost all the time ${ }^{b}$ & 0.69 & $0.34-1.39$ & .. & 1.08 & $0.48-2.39$ & .. & 1.11 & $0.61-2.02$ & .. \\
\hline No adjusted chair & 1.53 & $0.77-3.03$ & 0.23 & 0.68 & $0.30-1.56$ & 0.36 & 1.41 & $0.75-2.61$ & 0.29 \\
\hline No adjusted desk & 0.66 & $0.35-1.26$ & 0.20 & 1.03 & $0.51-2.09$ & 0.93 & 0.82 & $0.47-1.44$ & 0.49 \\
\hline No arm rest space & 0.91 & $0.56-1.47$ & 0.69 & 0.97 & $0.57-1.68$ & 0.93 & 0.98 & $0.63-1.52$ & 0.93 \\
\hline Screen below eye height & 1.03 & $0.68-1.55$ & 0.90 & 1.85 & $1.11-3.08$ & 0.014 & 1.20 & $0.82-1.75$ & 0.35 \\
\hline Never standing & 1.12 & $0.72-1.72$ & 0.92 & 0.86 & $0.53-1.40$ & 0.54 & 1.16 & $0.79-1.70$ & 0.46 \\
\hline Glares or reflection & 1.08 & $0.66-0.78$ & 0.76 & 1.20 & $0.70-2.07$ & 0.53 & 0.83 & $0.51-1.36$ & 0.46 \\
\hline Pauses, small influence & 1.87 & $1.05-3.33$ & 0.033 & 1.20 & $0.64-2.27$ & 0.57 & 1.15 & $0.68-1.95$ & 0.61 \\
\hline Necessary to work fast & 1.01 & $0.70-1.73$ & 0.68 & 1.15 & $0.69-1.92$ & 0.59 & 1.05 & $0.71-1.54$ & 0.82 \\
\hline Previous symptoms & 2.89 & $1.97-4.24$ & $<0.0001$ & 4.45 & $2.75-7.19$ & $<0.0001$ & 2.40 & $1.70-3.39$ & $<0.0001$ \\
\hline Cognitive demands & 1.00 & $0.98-1.02$ & 0.99 & 1.01 & $1.00-1.03$ & 0.14 & 1.01 & $0.99-1.02$ & 0.30 \\
\hline Sensory demands & 1.01 & $1.00-1.02$ & 0.12 & 1.00 & $0.99-1.02$ & 0.56 & 1.00 & $0.99-1.01$ & 0.76 \\
\hline Influence at work & 1.00 & $0.98-1.01$ & 0.51 & 1.00 & $0.98-1.02$ & 0.98 & 0.99 & $0.98-1.01$ & 0.31 \\
\hline Developmental possibilities & 1.00 & $0.99-1.02$ & 0.77 & 0.99 & $0.98-1.01$ & 0.46 & 0.99 & $0.98-1.01$ & 0.46 \\
\hline Social support & 1.00 & $0.99-1.01$ & 0.66 & 1.00 & $0.98-1.01$ & 0.53 & 1.01 & $0.99-1.01$ & 0.73 \\
\hline
\end{tabular}


Table 4. Continued.

\begin{tabular}{|c|c|c|c|c|c|c|c|c|c|}
\hline \multirow[t]{2}{*}{ Exposure factors } & \multicolumn{3}{|c|}{ Shoulder } & \multicolumn{3}{|c|}{ Elbow } & \multicolumn{3}{|c|}{ Back } \\
\hline & OR & $95 \% \mathrm{Cl}$ & P-value a & OR & $95 \% \mathrm{Cl}$ & P-value a & $\mathrm{OR}$ & $95 \% \mathrm{Cl}$ & P-value a \\
\hline \multicolumn{10}{|l|}{ Intensity } \\
\hline Worked $50 \%$ of the time ${ }^{b}$ & 1.07 & $0.60-1.90$ & 0.68 & 1.12 & $0.58-2.18$ & 0.62 & 0.94 & $0.54-1.62$ & 0.66 \\
\hline Worked $75 \%$ of the time ${ }^{b}$ & 0.95 & $0.53-1.70$ & .. & 0.90 & $0.47-1.74$ &.. & 1.20 & $0.70-2.07$ & .. \\
\hline Worked almost all the time ${ }^{b}$ & 0.78 & $0.43-1.43$ & .. & 1.08 & $0.48-2.39$ & .. & 1.25 & $0.72-2.18$ & .. \\
\hline No adjusted chair & 1.14 & $0.64-2.05$ & 0.66 & 1.22 & $0.61-2.43$ & 0.57 & 1.21 & $0.76-1.95$ & 0.89 \\
\hline No adjusted desk & 1.11 & $0.66-1.86$ & 0.71 & 0.90 & $0.49-1.65$ & 0.73 & 1.21 & $0.76-1.95$ & 0.43 \\
\hline No arm rest space & 0.95 & $0.63-1.43$ & 0.80 & 0.89 & $0.56-1.41$ & 0.62 & 0.92 & $0.62-1.36$ & 0.66 \\
\hline Screen below eye height & 1.16 & $0.80-1.68$ & 0.42 & 1.20 & $0.80-1.80$ & 0.38 & 0.98 & $0.69-1.37$ & 0.89 \\
\hline Standing, never & 1.11 & $0.77-1.60$ & 0.59 & 0.88 & $0.59-1.31$ & 0.53 & 1.34 & $0.81-1.60$ & 0.47 \\
\hline Glares or reflection & 1.55 & $1.05-2.30$ & 0.031 & 1.22 & $0.78-1.93$ & 0.39 & 1.14 & $0.77-1.69$ & 0.51 \\
\hline Pauses, small influence & 1.58 & $0.96-2.60$ & 0.072 & 1.06 & $0.62-1.82$ & 0.83 & 1.37 & $0.85-2.22$ & 0.20 \\
\hline Necessary to work fast & 0.98 & $0.67-1.43$ & 0.90 & 0.59 & $0.39-0.90$ & 0.014 & 1.14 & $0.80-1.63$ & 0.47 \\
\hline Previous symptoms & 1.64 & $1.18-2.29$ & $<0.001$ & 2.10 & $1.41-3.14$ & $<0.002$ & 1.40 & $1.02-1.92$ & 0.045 \\
\hline Cognitive demands & 1.01 & $0.99-1.02$ & 0.33 & 1.01 & $0.99-1.02$ & 0.39 & 1.00 & $0.99-1.02$ & 0.50 \\
\hline Sensory demands & 1.00 & $0.99-1.01$ & 0.65 & 1.01 & $0.99-1.02$ & 0.31 & 1.00 & $0.99-1.01$ & 0.65 \\
\hline Influence at work & 0.99 & $0.98-1.01$ & 0.34 & 0.99 & $0.98-1.00$ & 0.14 & 1.00 & $0.99-1.01$ & 0.56 \\
\hline Developmental possibilities & 0.99 & $0.98-1.01$ & 0.41 & 1.00 & $0.99-1.02$ & 0.86 & 1.00 & $0.99-1.01$ & 0.75 \\
\hline Social support & 1.00 & $0.99-1.01$ & 0.84 & 1.00 & $0.99-1.01$ & 0.44 & 0.99 & $0.99-1.00$ & 0.13 \\
\hline
\end{tabular}

a $P$-value refers to the likelihood-ratio test, and those below 0.10 are in bold face.

b With a computer.

shoulder, whereas work with a screen below eye height was a significant predictor of symptoms in the elbow.

An important strength of our study was its prospective design, including measurements of the exposure prior to the occurrence of symptoms. In comparison with the design of previous cross-sectional studies, this approach offered the possibility to identify predictors of increased symptoms. People who change jobs are more likely to be relieved of their pain (25). In order to control for exposure at follow-up, we repeated the use of the final model for each of the three regions including only the workers who, in the follow-up questionnaire, had not changed jobs since the baseline examination. In these analyses the predictors for becoming symptomatic were confirmed, as the odds ratios did not change markedly.

As in most epidemiologic studies, our outcome and exposure variables were self-reported. In order to obtain a broad pattern of symptoms, we used two variables as the self-reported outcome variables, the frequency and intensity of symptoms. The question concerning frequency, which covered days of symptoms within the last 12 months, rated on a 5-point scale, was fairly easy to answer, although recall bias may have caused a problem, as in many other epidemiologic studies. Furthermore, it is the most used outcome variable in recent epidemiologic and intervention studies. The mean intensity of symptoms, which covered only the last 3 months, rated on a 0-9 point scale, was a more complicated problem, as it had to be weighted individually according to the worst and least intensity of the same period. It is a variable that is becoming used more and more in epidemiologic studies as a supplement to the frequency variable. The cut-off point of $\leq 7$ days and the intensity score of $\leq 3$ were selected as arbitrary cut-off points so that a large study population would be included. Moderate correlations $\left(\mathrm{R}^{2} 0.36-0.45\right)$ were found between the frequency and intensity variable. This result indicated that frequency and intensity are different measures of self-reported symptoms. Furthermore, as only a few of the significant predictors were the same for the frequency and the intensity outcome variables, we considered it important to include both outcome variables in the analyses. Although many studies have used the terminology neck-shoulder as one region, we defined the two regions separately in this study, shown in the drawing of the questionnaire lay-out, and, thereby, retained the possibility to look for specific risk factors in the regions separately. In addition, only a few of the respondents (9.8\% for frequency and $11.2 \%$ for intensity) had developed symptoms in both the neck and shoulder region by the time of the follow-up.

As with the outcome variable, the general problem of using self-reported data in epidemiologic studies also exists for exposure variables, and, consequently, only the variables easily assessed by respondents can be studied. Self-reported exposures measure perceived job demands and therefore do not necessarily reflect objective measured job demands (26). Other conditions that may influence self-reported exposures are the presence of musculoskeletal symptoms (27). One of the exposure variables " influence on when to take a workpause", was not included in the variable "influence at work", although a significant and relatively high correlation $\left(\mathrm{R}^{2}=0.55\right)$ was found between the two variables. In the full-fit model, however, only the influence on workpauses was 
significant. When we omitted the pause variable for each of the three body-region models, influence at work did not become significant. This result confirmed that the two represented different conditions and emphasized the importance of having both variables in the statistical models.

Having had previous symptoms was a significant predictor of symptoms in the shoulder, the elbow, and the low back, as has also been found in previous studies $(6,12,28)$. This finding underlines a chronicity aspect (ie, that musculoskeletal pain may have a progressive course towards chronicity) that begins with intermittent periods of pain and ends in a more continuous or persistent period of pain.

Although many cross-sectional studies have found that worktime with a computer is a risk factor for almost all body regions (29), our study did not confirm this finding for any of the tested regions. In addition our results are in contrast to the findings of a cross-sectional study of the same population $(17,18)$. This difference emphasized the importance of performing prospective studies when risk factors are to be studied. Thus, so far, the best evidence for worktime with a computer as a predictor of future musculoskeletal symptoms has been found in prospective studies on the hand and wrist $(6,7,30)$, and also for those on the duration of mouse use with respect to the forearm and shoulder $(11,31)$.

A small influence on when to take a rest pause, which includes biomechanical elements such as decreased restitution periods leading to pain or even clinical diagnoses, has been found in several studies. A cross-sectional study found a lower frequency of muscular rest periods (EMG gaps) in the shoulder muscle (trapezius) of persons with pain in the trapezius area than in healthy controls (32). A few prospective studies have also found that a low frequency of muscular rest periods for the trapezius muscle is a predictor of trapezius myalgia (33) and that repetitive work with a low recovery time was a predictor of symptoms and of clinical signs in the neck and shoulder area (34).

In addition, being disturbed by glare or reflection was a significant predictor of symptoms in the shoulder as well; this finding may be explained by a changed work posture being adopted in order to avoid or decrease the inconvenience of the glare or reflection, which have also been found to predict neck symptoms (6). In general, a large index number within the psychosocial dimensions has previously been found to be associated with increased symptoms in the shoulder in cross-sectional and prospective studies of repetitive work (3538). Surprisingly, none of these dimensions were significant in our full-fit model, although in the psychosocial submodel sensory demands, influence at work and developmental possibilities were significant predictors of symptoms in the shoulder, cognitive demands predicted symptoms in the elbow, and influence at work predicted symptoms in the low back. In an earlier report from the BIT study, low influence at work was reported to be a predictor of symptoms primarily in the hand and wrist (6), but our study did not confirm this finding.

For women, a computer screen placed in a high position (above eye height) has been found to be a predictor of neck symptoms (6), whereas, in our study, a screen below eye height was a significant predictor of symptoms in the elbow. This difference may be explained by a combined low screen and keyboard height, which would decrease the possibility to rest and relax the elbow and forearm sufficiently. A low satisfaction with the physical arrangement of the computer workstation and workers' perception of their workstation as being poor ergonomically has also been found to be associated with an increased prevalence of pain in the neck and upper extremities in cross-sectional studies $(39,40)$. Important risk factors for lateral epicondylitis are nonneutral postures of the hands and arms and a combination of nonneutral postures of hands and arms, repetition, and forceful work (10). One of the main diagnoses related to forearm pain, lateral epicondylitis, has been found to include degenerative signs of the tendons around the lateral epicondyle (especially the tendon of the radial extensor muscle of the wrist) (41). As often found during the use of traditional computer input devices (text-entering and text-editing work), characterized as low force pronation and wrist extension, the radial extensor muscle of the wrist has high muscle activity (42). The fact that a great necessity to work fast decreased the risk of symptoms in the elbow could not be explained.

None of the variables studied were significant for the development of symptoms in the low back in the final full-fit model, despite tendencies towards significance for influence on pauses, influence at work, and worktime with the computer in the ergonomic and psychosocial submodels. A small influence on when to take a workpause, meaning a longer duration of sitting, was expected to have an influence on the back, as also found previously (15). In contrast, a systematic review found no evidence of an effect on low-back pain for prolonged sitting (43).

In conclusion, a small influence on when to take a workpause and being disturbed by glare and reflection of the screen were predictors of symptoms in the shoulder, while a screen below eye height was a significant predictor of symptoms in the elbow. Having had previous symptoms was a predictor of future symptoms in all the regions studied, and this result emphasizes the persistence of musculoskeletal symptoms. In contrast to the results of other studies, worktime with the computer and psychosocial dimensions were not significant predictors of symptoms in the shoulder, elbow, or low back. 


\section{Acknowledgments}

The BIT study was initiated as part of research involving both epidemiologic and laboratory studies focusing on the musculoskeletal problems of computer users. Therefore, we would like to thank K Hansen, CU Ryholt, AK Blangsted, L Finsen, E Villadsen, and H Christensen for their efforts during the course of the BIT study.

\section{References}

1. Punnett L, Bergqvist U. Musculoskeletal disorders in visual display unit work: gender and work demands. Occup Med 1999;14:113-24.

2. Tittiranonda P, Burastero S, Rempel D. Risk factors for musculoskeletal disorders among computer users. In: Cherniak M, editor. Philadelphia (PA): Hanley \& Belfus, Inc; 1999. Occupational medicine: state of the art reviews14(1), janmar:17-38.

3. Punnett L, Bergqvist U. Visual display unit work and upper extremity musculoskeletal disorders: a review of epidemiological findings. Solna (Sweden): National Institute for Working Life; 1997. Ergonomic expert committee document no $1: 1-161$.

4. Jensen C, Borg V, Finsen L, Hansen K, Juul-Kristensen B, Christensen H. Job demands, muscle activity and musculoskeletal symptoms in relation to work with the computer mouse. Scand J Work Environ Health 1998;24(5):418-24.

5. Blangsted AK, Søgaard K, Christensen H, Sjøgaard G. The effect of physical and psychosocial loads on the trapezius muscle activity during computer keying tasks and rest periods. Eur J Appl Physiol 2004;91:253-8.

6. Jensen C. Development of neck and hand-wrist symptoms in relation to duration of computer use at work. Scand J Work Environ Health 2003;29(3):197-205.

7. Marcus M, Gerr F, Monteilh C, Ortiz DJ, Gentry E, Cohen S, et al. A prospective study of computer users, II: postural risk factors for musculoskeletal symptoms and disorders. Am J Ind Med 2002;41:236-49.

8. Korhonen T, Ketola R, Toivonen R, Luukkonen R, Häkkänen $\mathrm{M}$, Viikari-Juntura E. Work related and individual predictors for incident neck pain among office employees working with video display units. Occup Environ Med 2003;60:475-82.

9. Bernard B. Musculoskeletal disorders and workplace factors: a critical review of epidemiologic evidence for work-related musculoskeletal disorders of the neck, upper extremity, and low back. Cincinnati $(\mathrm{OH})$ : US Department of Health and Human Services, National Institute for Occupational Safety and Health; 1997. p 1-C-59.

10. Haahr JP, Andersen JH. Physical and psychosocial risk factors for lateral epicondylitis: a population based case-referent study. Occup Environ Med 2003;60:322-9.

11. Kryger A, Andersen JH, Lassen CF, Brandt L, Vilstrup I, Overgaard E, et al. Does computer use pose an occupational hazard for forearm pain; from the NUDATA study [electronic paper]. Occup Environ Med 2003;60:e14.

12. Haahr JP, Andersen JH. Prognostic factors in lateral epicondylitis: a randomized trial with one-year follow-up in 266 new cases treated with minimal occupational intervention or the usual approach in general practice. Rheumatology $(\mathrm{Br})$ 2003;42:1-10.

13. Hartvigsen J, Leboeuf-Yde C, Lings S, Corder EH. Is sittingwhile-at-work associated with low back pain?: a systematic, critical review. Scand J Public Health 2000;28:230-9.

14. Lee Y-H, Chiou W-K. Risk factors for low back pain, and patient-handling capacity of nursing personnel. J Saf Res 1994;25:135-45.

15. Rotgoltz J, Derazne E, Froom P, Grushecky E, Ribak J. Prevalence of low back pain in employees of a pharmaceutical company. Isr J Med Sci 1992;28:615-8.

16. Hartvigsen J, Bakketeig LS, Leboeuf-Yde C, Engberg M, Lauritzen, T. The association between physical workload and low back pain clouded by the 'Healthy worker' effect. Spine 2001;26:1788-93.

17. Jensen C, Ryholt CU, Burr H, Villadsen E, Christensen H. Work-related psychosocial, physical and individual factors associated with musculoskeletal symptoms in computer users. Work Stress 2002;16:107-120.

18. Jensen C, Finsen L, Søgaard K, Christensen H. Musculoskeletal symptoms and duration of computer and mouse use. Int $\mathrm{J}$ Ind Ergon 2002;30:265-75.

19. Kuorinka I, Jonsson B, Kilbom Å, Vinterberg H, BieringSørensen F, Andersson G, et al. Standardised Nordic questionnaires for the analysis of musculoskeletal symptoms. Appl Ergon 1987;18:233-7.

20. Demure B, Luippold RS, Bigelow C, Ali D, Mundt KA, Liese B. Video Display Terminal workstation improvement program, I: Baseline associations between musculoskeletal discomfort and ergonomic features of workstations. J Occup Environ Med 2000;42:783-91.

21. Ketola R, Toivonen R, Häkkänen M, Luukkonen R, Takala E-P, Viikari-Juntura E, et al. Effects of ergonomic intervention in work with video display units. Scand J Work Environ Health 2002;28(1):18-24.

22. Brauer C, Thomsen JF, Loft S, Mikkelsen S. Can we rely on retrospective pain assessments? Am J Epidemiol 2003;Mar 15:552-7.

23. Kaergaard A, Andersen, JH, Rasmussen K, Mikkelsen S. Identification of neck-shoulder disorders in a 1 year followup study: validation of a questionnaire-based method. Pain 2000;86:305-10.

24. Kristensen TS, Borg V, Hannerz H. Socioeconomic status and psychosocial work environment: result from a national Danish study. Scand J Public Health 2001;41-8.

25. Schibye B, Skov T, Ekner D, Christiansen JU, Sjøgaard G. Musculoskeletal symptoms among sewing machine operators. Scand J Work Environ Health 1995;21:427-34.

26. Blangsted AK, Hansen K, Jensen C. Muscle activity during computer-based office work in relation to self-reported job demands and gender. Eur J Appl Physiol 2003;89:352-8.

27. Mikkelsen S, Butcher I, Andersen JH, Lassen CF, Brandt L, Kryger A, et al. Factors influencing self-reported computer use compared to objectively measured computer use in the NUDATA study. In: The challenge of equity in safety and health at work [CD-ROM]. 27th International Congress on Occupational Health (ICOH), February 23-28, Iguassu, Brazil. Iguassu (Brazil): International Commission of Occupational Health; 2003. p 49.1.

28. Maul I, Laubli T, Klipstein A, Krueger H. Course of low back pain among nurses: a longitudinal study across eight years. Occup Environ Med 2003;60:497-503.

29. Fogleman M, Lewis RJ. Factors associated with self-reported musculoskeletal discomfort in video display terminal (VDT) 
users. Int J Ind Ergon 2002;29:311-8.

30. Bergqvist U. Visual display terminal work-a perspective on long-term changes and discomforts. Int J Ind Ergon 1995;16:201-9.

31. Brandt L, Lassen CF, Kryger A, Andersen JH, Mikkelsen S, Overgaard E, et al. Incidence of neck and shoulder disorders among technical assistants and machine technicians in Denmark-results from a 1 year follow-up in the NUDATA study. In: The challenge of equity in safety and health at work [CD-ROM]. 27th International Congress on Occupational Health (ICOH), February 23-28, Iguassu, Brazil. Iguassu (Brazil): International Commission of Occupational Health; 2003. p 26.8.

32. Hägg GM, Åström A. Load pattern and pressure pain threshold in the upper trapezius muscle and psychosocial factors in medical secretaries with and without shoulder/neck disorders. Int Arch Occup Environ Health 1997;69:423-32.

33. Veiersted KB, Westgaard RH, Andersen P. Electromyographic evaluation of muscular work pattern as a predictor of trapezius myalgia. Scand J Work Environ Health 1993; 19:284-90.

34. Andersen JH, Kaergaard A, Jensen UF, Frost P, Bonde JP, Fallentin N, et al. Risk factors in the onset of neck/shoulder pain in a prospective study of workers in industrial and service companies. Occup Environ Med 2003;2003:649-54.

35. Andersen JH, Kaergaard A, Frost P, Thomsen JF, Bonde JP, Fallentin N, et al. Physical, psychosocial and individual risk factors for neck/shoulder pain with pressure tenderness in the muscles among workers performing monotonous, repetitive work. Spine 2002;27:660-7.

36. Marcus M, Gerr F. Upper extremity musculoskeletal symp- toms among female office workers: associations with video display terminal use and occupational psychosocial stressors. Am J Ind Med 1996;29:161-70.

37. Feveile H, Jensen C, Burr H. Risk factors for neck-shoulder and wrist-hand symptoms in a 5-year follow-up study of 3,990 employees in Denmark. Int Arch Occup Environ Health 2002;75:243-51.

38. Kaergaard A, Andersen JH. Musculoskeletal disorders of the neck and shoulders in female sewing machine operators: prevalence, incidence, and prognosis. Occup Med 2003; 57:528-34.

39. Ferreira M, Saldiva HN. Computer-telephone interactive tasks: predictors of musculoskeletal disorders according to work analysis and workers' perception. Appl Ergon 2002;33:147-53.

40. Sillanpää J, Huikko S, Nyberg M, Kivi P, Laippala P, Uitti J. Effect of work with visual display units on musculoskeletal disorders in the office environment. Occup Med 2003; 53:443-51.

41. Johnstone AJ. Tennis elbow and upper limb tendinopathies. Sports Med Arthr Rev 2000;8:69-79.

42. Juul-Kristensen B, Laursen B, Pilegaard M, Jensen BR. Physical workload during use of speech recognition and traditional computer input devices. Ergonomics 2004;47:119-33.

43. Hoogendoorn WE, van Poppel MNM, Bongers PM, Koes BW, Bouter LM. Physical load during work and leisure time as risk factors for back pain [review]. Scand J Work Environ Health 1999;25(5):387-403.

Received for publication: 1 December 2003 